\title{
Erratum to: CYP3A4 and seasonal variation in vitamin D status in addition to CYP2D6 contribute to therapeutic endoxifen level during tamoxifen therapy
}

\author{
Wendy A. Teft • Inna Y. Gong • Brian Dingle • Kylea Potvin • Jawaid Younus • \\ Theodore A. Vandenberg • Muriel Brackstone • Francisco E. Perera • \\ Yun-Hee Choi • Guangyong Zou • Robin M. Legan • Rommel G. Tirona • \\ Richard B. Kim
}

Published online: 28 September 2013

(C) Springer Science+Business Media New York 2013

Erratum to: Breast Cancer Res Treat (2013)

139:95-105

DOI 10.1007/s10549-013-2511-4

In the original publication of the article, due to rather complex formulas used, a few of the calculations for

Electronic supplementary material The online version of this article (doi:10.1007/s10549-013-2706-8) contains supplementary material, which is available to authorized users.

The online version of the original article can be found under doi:10.1007/s10549-013-2511-4.

W. A. Teft · I. Y. Gong · R. M. Legan ·

R. G. Tirona · R. B. Kim

Division of Clinical Pharmacology, Department of Medicine,

University of Western Ontario, London, ON, Canada

I. Y. Gong · R. G. Tirona - R. B. Kim

Department of Physiology and Pharmacology, University of

Western Ontario, London, ON, Canada

B. Dingle $\cdot$ K. Potvin $\cdot$ J. Younus $\cdot$ T. A. Vandenberg .

M. Brackstone · F. E. Perera · R. B. Kim

Department of Oncology, University of Western Ontario,

London, ON, Canada predicted endoxifen level may give erroneous values. The correct version of the Electronic Supplementary Material is given in the link below.

\footnotetext{
M. Brackstone

Department of Surgery, University of Western Ontario, London,

ON, Canada

Y.-H. Choi · G. Zou

Department of Epidemiology and Biostatistics, University of

Western Ontario, London, ON, Canada

R. B. Kim ( $($ )

Department of Medicine, LHSC-University Hospital,

Room A-LL-152, 339 Windermere Road, London,

ON N6A 5A5, Canada

e-mail: richard.kim@lhsc.on.ca
} 